Tirant, 23 (2020)

Literatura de caballerías:

entidad receptora y difusora de un pensamiento moderno

Chivalric literature:

Welcoming and Diffusing Entity of a Modern Thought

Monográfico coordinado por

Juan Pablo Mauricio García Álvarez 



\title{
Literatura de caballerías: entidad receptora y difusora de un pensamiento moderno
}

\author{
Chivalric literature: \\ Welcoming and Diffusing Entity of a Modern Thought \\ Presentación \\ Juan Pablo Mauricio García Álvarez \\ (Universidad de Heidelberg)
}

\section{RESUMEN}

Justificación de los presupuestos teóricos sobre la temática de este monográfico. Además, se presentan y reseñan los acercamientos críticos en los trabajos aquí reunidos. La línea directriz de todos ellos sería el análisis de las trazas de pensamiento moderno en los libros de caballerías, ya sea por las estrategias utilizadas por sus autores para la configuración del texto, ya por los significados que articulan estas obras, permeadas de las principales problemáticas culturales, sociales, políticas y económicas de la época. Los libros de caballerías se convirtieron en verdaderos receptáculos y difusores de las distintas posibilidades de interpretar la realidad, y ver y representar el mundo.

\section{Palabras clave}

Libros de caballerías, pensamiento moderno, Temprana Edad Moderna, Humanismo vulgar, estrategias literarias.

\begin{abstract}
Justification of the theoretical assumptions on the subject of this monograph. In addition, the critical approaches of the works collected here are exposed and reviewed. The main goal of these articles consists in the analysis of early modernity thought in the chivalric books, either by the literary strategies used for the configuration of the text or due to the meanings permeated by the main cultural, social, political and economic problems. The chivalric books, thus, became a receptacle and diffuser of different interpretations of reality and world perspective.
\end{abstract}

\section{KEYWORDS}

Chivalric literature, Modern thought, Early Modern Age, Popular Humanism, Literary strategies.

Recibido: $27 / 07 / 2020$

Aceptado: 30/09/2020 
La composición, impresión y difusión de la literatura de caballerías de ficción tuvo su mayor auge dentro de una circunstancia temporal que se caracterizó por el constante y cambiante dinamismo de las distintas aristas que conformaron la realidad en un momento histórico como el comprendido por la temprana modernidad ${ }^{1}$. Este periodo se singularizó por manifestarse un avance en cuanto a la forma de comunicarse (avance tecnológico, modos de comportamiento ...), privilegiar la razón por encima de una imposición, o, al menos, delimitar la manera en la que se podría lograr un objetivo particular sin que fuera perjudicial al individuo o a la sociedad misma; así como por la búsqueda de un pasado anterior (Edad Clásica) que permitiera encontrar un sentido crítico del presente para elaborar soluciones viables ante disputas y controversias que atentaran en contra del beneficio de la comunidad (res publica $)^{2}$. Es necesario tener esto presente para comprender e interpretar los cambios que venían ocurriendo: el nacimiento de una mentalidad de expansión y de posesión material (un incipiente capitalismo), en que el mérito y la riqueza conformaban los nuevos valores identitarios, lo que derivaría en una contienda dialéctica entre la posibilidad de acceder o no a una entidad estamental, en una apertura de fe a la que el hombre se enfrentaba con sus medios personales a la naturaleza divina (luteranismo, calvinismo, Reforma, Concilio de Trento) y, sobre todo, en el acceso a un pensamiento cinético que, gracias a la interacción e interrelación de territorios y formas de concebir el mundo, basaba su configuración en la experiencia de una práctica cultural integral.

Pero vayamos por partes. La institución de la caballería, como han mostrado diversos críticos y estudiosos ${ }^{3}$, ayudaría a legitimar desde la Edad Media una serie de acciones, creadas por diversos actores pertenecientes tanto al ámbito monárquico como a los principales órganos imanadores de conocimiento, para constituir los cimientos y las acciones necesarias que permitirían delinear una nueva perspectiva de mundo en los siglos XVI y XVII, tratando de ir de la mano con los cambios políticos, económicos, sociales y culturales que venían sucediendo en territorio europeo y en el Nuevo Mundo. La intención de este ejercicio intelectual consistió principalmente en otorgar un funcionamiento adecuado a cada engranaje perteneciente al aparato de poder de la monarquía hispánica y en procurar la armonía necesaria para crear un desarrollo, según el cual el pensamiento individual y colectivo que se intentaban fomentar y transmitir se convertiría en una entidad necesaria para comprender, ser y hacer una nueva realidad, amparada bajo un idea común y amplia, al menos en un nivel primario.

En la literatura caballeresca, tanto ficcional como teórica-práctica ${ }^{4}$, se buscaría dar muestra palpable del desarrollo de nuevas organizaciones económicas y de sistemas políticos de gobierno; también se intentaba ilustrar el debate que se derivaba de la integración de nuevas capas sociales, que ya no necesitaban de un condicionante como pertenecer a un linaje para posicionarse dentro del ámbito de la nobleza. Con ello se ponía en controversia la importancia de las obras ejecutadas por el individuo, a veces por encima de lo que significaba pertenecer directamente a una familia. Se daba cuenta, asimismo, del desarrollo creciente de una burocracia y un conjunto de letrados como una extensión del aparato monárquico. Ese poder ayudaría a consolidar una serie de ideas, en cuyo seno se buscaba primar el conocimiento para establecer medidas indispensables, con la finalidad de resolver distintos conflictos que atentaran contra la armonía y buena salud del go-

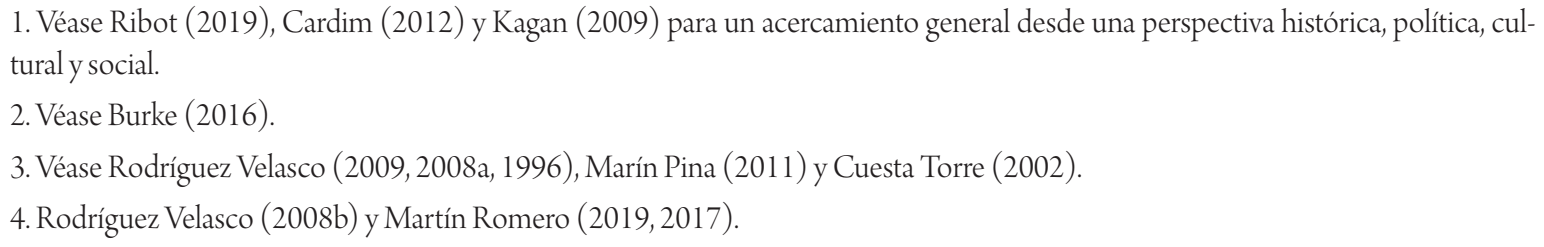


bierno. La diplomacia se posicionaba allí, por momentos, como eje de acción, aun por encima de pensar en una resolución bélica, como alternativa y entre otras problemáticas que tenían cabida dentro de este tipo de discurso.

Ante esto, los escritores de ficción caballeresca optarían por realizar y concebir una suerte de humanismo vulgar, entendiendo por este término no el contenido semántico de lo que implicaba la voz humanismo de manera estricta, sino la puesta en escena de circunstancias de diversa naturaleza (política, economía, social y cultural) dentro de la historia de ese universo imaginario, circunstancias que ayudaron al establecimiento y acrecentamiento de un tipo de pensamiento que correspondía al interés de comprender la realidad ${ }^{5}$. Y ello gracias a la correlación, bajo parámetros conocidos, entre las problemáticas cotidianas y las situaciones que se presentaban en sus textos. Por ejemplo, la disyuntiva ante la cuestión de la división de territorios obtenidos y sobre quién o quiénes estarían a cargo de estos en cada uno de los órganos que harían funcionar el gobierno hasta el retorno del caballero para tomar posesión de sus dominios, como se lee en Claribalte 6 , en un verdadero remedo de lo que sucedía en el mundo real ${ }^{7}$. O la práctica de un juicio en el que se determinaría la culpabilidad de un caballero al matar a otro en defensa propia, entre otras temáticas y materias ${ }^{8}$. Dichas estrategias literarias se ponían al alcance de un público amplio, heterogéneo -no exclusivamente letrado o informado sobre temáticas particulares-, pero que poseía la capacidad suficiente para descodificar lo ahí planteado.

No debemos olvidar que los autores de libros de caballerías pertenecieron a un círculo muy próximo al monarca y se encontraban al servicio de personas poderosas, que desempeñaban un papel definitorio en la articulación de la monarquía hispánica e imperial; además, serían estos sus principales receptores, al ejercer la función de dedicatarios de los textos, siendo incluso algunos miembros de la familia real. Gracias a ello las situaciones relatadas, las actitudes de los personajes protagonistas y la interrelación de estos con otros entes de ficción, así como las alusiones directas o indirectas a personas pertenecientes a la nobleza ${ }^{9}$, permitirían una reflexión sobre ciertos cuestionamientos prácticos, y lo harían a partir de lo ficcional y mediante una distancia que posicionaría al lector y oyente ante lo sucedido en el plano textual como un intérprete de una realidad.

5. Ante esto parece necesario un estudio sobre la relación entre el contexto salmantino y la primera producción de libros de caballerías impresas, precisamente en Salamanca, después de la aparición del Amadís de Gaula, ya que el Florisando de Paéz de Ribera, los dos primeros libros del ciclo de los palmerines (Palmerín de Olivia y Primaleón) y el Lisuarte de Grecia de Feliciano de Silva pareceren responder a un experimento literario amplio, en donde tenían cabida materiales que no se adaptaban a lo postulado por Rodríguez de Montalvo en su refundición amadisiana y en las Sergas de Esplandián. Ello nos ayudaría a delimitar tanto los cauces novelescos como los campos de acción intelectual que perseguían los autores en un contexto universitario y humanista, dentro del periodo comprendido entre 1510 y 1514. Además de la influencia que dichos textos ejercieron en el género.

6. En concreto, de los capítulos LII al LXI. No debemos olvidar que Fernández de Oviedo estaba familiarizado con los textos de regimiento de príncipes.

7. Véase Martínez Muñoz (2017), quien en su tesis de doctorado sobre el Mexiano de Esperanza ofrece una lectura en clave histórica de la ficción de este libro de caballerías.

8. Así ocurre en el Lepolemo, cuando el protagonista, que debe tomar las armas para defender su vida, es sometido a juicio por realizar esta acción, dirimiéndose allí si su actuación fue en defensa propia, o con alevosía y ventaja.

9. Pensemos en el ejemplo del Palmerín de Olivia, cuyo autor incita en el prólogo del texto a que Luis de Córdoba recuerde lo realizado por otros integrantes de su familia en la guerra de Granada y en Nápoles, a partir de las aventuras realizadas por el protagonista de la novela. Esta estratategia de persuasión será llevada más allá cuando Francisco Delicado integre un prólogo a la edición veneciana de 1534, en donde halle una correspondencia directa entre los personajes de ficción y personas contemporáneas a la publicación de los textos y que efectuaron algún acto gallardo. 
Hablamos, entonces, de un discurso literario que, si bien tuvo como uno de sus principales móviles el entretenimiento, también dio cabida a una serie de componentes propios del imaginario cultural y del pensamiento intelectual del momento. La ficción de caballerías supuso, así, una herramienta que permitió materializar preocupaciones palpables entre un público que se vio en varias ocasiones, ya no sólo identificado en las obras mediante las emociones que se desprendían por su lectura, sino reflejado en algunos acontecimientos que podían formar parte de una mentalidad compartida que comenzaba a abrirse a otros tenores. El mundo de los libros de caballerías -y de los relatos impregnados de la misma materia literaria- se irá extendiendo hasta llegar a constituir verdaderos postulados teóricos o debates, por ejemplo, sobre los efectos producidos en el individuo por el sentimiento amoroso, con auténticas reflexiones sobre las implicaciones que conlleva enamorarse y la concreción de poseer al objeto de deseo por todos los medios posibles y al alcance ${ }^{10}$. Algunos títulos incluso se constituirán como verdaderos manuales de cortesanía, al delimitar las normas que se deberían guardar en distintas situaciones de palacio y fuera de él, conformando un verdadero catálogo de donaires y de historias que podrían ser relatadas en momentos de reunión. También se puede encontrar en sus páginas episodios en donde se imbrica la ciencia del blasón como una ayuda para potenciar el significado de ciertos elementos y en distintos registros: bélicos, amorosos, cómicos, etc. Son ejemplo ilustrativo los componentes heráldicos y emblemáticos sobre los que se construye el episodio de la aventura de la Cueva de Hércules del Clarían de Landanís, donde la referencia a la orden del Toisón de Oro, sumada a la conexión entre la tradición caballeresca borgoñona y la ciudad imperial española, ejerce la función de texto legitimador de una memoria histórica que pretendía validar la idea de que Carlos I de España y V de Alemania se convirtiera en el nuevo monarca hispánico, al carecer de una crónica que lo posicionara con firmeza dentro de la cultura castellana y aragonesa. Éste, entre otros muchos ejemplos se puede rastrear y localizar en el corpus de los libros de caballerías ${ }^{11}$.

Sin embargo, y aunado a lo anterior, este tipo de obras fue además un repositorio experimental de diversas estrategias literarias e imbricaciones genéricas; un verdadero laboratorio estilístico que dio lugar a una concepción moderna del quehacer literario. Los autores adaptaron materiales varios a sus necesidades creativas, incluso reflexionando sobre las propias convenciones del género, su pertinencia, variación y refuncionalización. Algunos escritores se adentraron en otros géneros literarios, lo que sin duda estimuló y abrió su concepción de la ficción a nuevos objetivos que intentaron postular en su producción caballeresca. Y estos postulados creativos fueron más allá ya que, gracias a la formulación de un pensamiento moderno, mostraron a la ficción de caballerías como un conjunto aglutinador y totalizador en donde varios elementos podían tener cabida bajo el amparo de una armonía funcional. Los libros y sus representaciones servían de canal de comunicación de prácticas culturales heterogéneas. Se diría que los libros de caballerías eran espirales en cuyo eje transversal permeaba la historia de un caballero en busca de fama y honor mediante la realización de acciones valerosas, sostenidos con fuerza necesaria por el amor de una doncella; un caballero con la misión de procurar introducir el orden en cada uno de los territorios a los que tenía acceso. Pero, además -y creo que más importante aún-, las curvas delineadas alrededor de este foco darán cuenta de realidades alternas y paralelas al texto principal, que adquieren rele-

10. Pensemos en la constante defensa de la libertad de decisión, sobre todo en los personajes femeninos que aparecen en las novelas de caballerías de Feliciano de Silva, además de la constante reflexión sobre el sentir amoroso y los alcances que éste tiene en los distintos personajes que lo padecen.

11. Véase Eisenberg y Marín Pina (2000). 
vancia significativa al instaurarse como una suerte de periscopio que permite observar los niveles profundos tanto de codificación como de interpretación sobre temas y materiales que conciben y plasman una misma realidad desde distintas perspectivas.

Testimonio de algunos de los aspectos aquí apuntados son los trabajos reunidos en el presente monográfico, que enmarcan a través derroteros distintos y delinean a partir de lecturas críticas plurales parte del pensamiento y objetivos que acompañarían a los autores que decidieron inscribir sus libros de caballerías en la historia del libro impreso, otorgando a sus empresas literarias una apertura temática, con la finalidad de circunscribir una imagen del mundo a una realidad cambiante y reestructuradora como lo fue la temprana modernidad.

El monográfico se divide en dos apartados. El primero versa sobre los nuevos itinerarios creativos por los que los autores hacen discurrir sus obras y sobre los ecos que ayudarían a incrementar las posibilidades del quehacer literario del género y a definir narrativas futuras. Algo que significó un proceso de integración, gracias al contacto fluido y directo de la ficción con la historia, mediante la creación de una entidad cultural que buscara en la tradición literaria fundamentar una identidad individual. El segundo apartado está integrado por trabajos que desvelan un nivel profundo de significado de obras caballerescas que potencian la función de la ficción para revelar el pensamiento del individuo de la época y algunas de las preocupaciones palpables en ese contexto puestas en acción por personajes literarios: programas de política económica, una cultura de la vestimenta, el inicio de una relatividad religiosa y la asimilación de lo espectacular caballeresco en otro género, el teatral. Esta capacidad de la literatura posibilita interpretaciones particulares del mundo a partir de la puesta en escena de las virtualidades caballerescas.

La primera parte del monográfico se inicia con el artículo de Maribel Ayala Rodríguez ( $\ll$ La función del nombre y sus cambios en la conformación de la identidad del héroe en Espejo de príncipes y caballeros de Diego Ortúñez de Calahorra»), quien analiza la importancia significativa de que el Caballero del Febo decida no recibir otro nombre -o sobrenombre-por parte de otro personaje, con el fin de ocultar su identidad. El narrador no vacila ante -ni reprocha- esa decisión, lo cual llama la atención, ya que el uso de esta función onomástica atípica en los libros de caballerías resaltará la capacidad de Ortuñez de Calahorra por otorgar al protagonista de su novela una identidad única a lo largo de todo el texto. Desde esta perspectiva analítica, la ruptura de este caballero frente a sus pares en otros títulos del género llama la atención, debido a que se dejan de lado los usos literarios tópicos de una estrategia literaria habitual que consistía en hacer constante la utilización plurinominal del caballero para crear una identidad a partir de la construcción y caracterización de su vida heroica desde distintos puntos de vista. Ayala Rodríguez, también puntualiza la difícil decodificación en la realidad textual para la develación y anagnórisis familiar que el caballero deberá realizar para saber su verdadero origen. Éste, señala la autora, no se convierte en móvil de acción para el personaje; al contrario, la falta de transparencia nominal ante otros entes de ficción permite al lector convertirse en una suerte de cómplice en varios episodios en que la lengua jugará un papel importante, ya que, como se indica en la novela, el Caballero del Febo es criado en su niñez en una corte no cristiana, por lo que su nombre se pronuncia en lengua persa, aspecto que dificultará cualquier indicio para revelar su parentesco familiar, a pesar de contar con la marca corporal necesaria para ello. A pesar de una breve mutatio nominis, que responde estructuralmente a la resolución de la temática amorosa y la develación del linaje, la autora insiste que la extensión semántica delimitada hasta esos episodios 
de la novela que, si bien no afectan la individualidad del caballero, forman parte del rito de paso tradicional presente en el género, tanto para descubrir la correspondencia amorosa entre el caballero y la dama cuanto para facilitar el reconocimiento consanguíneo. Por tanto, la construcción de la identidad del Caballero del Febo no dependerá de ocultar su naturaleza, como ocurre en otros libros de caballerías con distintos caballeros, sino que apelará a la transmisión singular y personal de los hechos de un personaje que no necesita encubrirse para realizar las acciones necesarias que le permitan obtener fama y honra; con esto se insiste en una dignidad personal que en todo momento se hace explícita en el mundo textual y de la que se hace copartícipe al lector.

Julia Navarro puntualiza la apertura al tratamiento paradigmático de la magia que se había desarrollado en los libros de caballerías hasta la aparición del Amadís de Grecia. En su artículo ( «La Gloria de Niquea y la Torre del Universo: dos edificaciones mágicas subordinadas al ars narrandi de Feliciano de Silva») señala una nueva estructura de las edificaciones mágicas desde el entramado narrativo en la obra de Feliciano de Silva, ya que este escritor recurría a la imbricación genérica, por momentos, para otorgar mayor dinamismo a una temática altamente codificada en el género caballeresco, e incluso echará mano del entrelazamiento para demarcar el linaje de Amadís y su concepción del amor. Uno de los elementos que resalta la autora es la inclusión de los personajes de manera más directa al formar parte de la arquitectura mágica, una suerte de naturaleza tridimensional, pues los involucrados en la resolución de las pruebas se convertirán tanto en actores como en espectadores de lo allí sucedido. Por ejemplo, en «La Gloria de Niquea», según Navarro, la narración de la prueba se configura a partir del hecho de evitar un incesto entre hermanos, Niquea y Anastárax, y alrededor de esta premisa se crearán una serie de expectativas tanto para los personajes involucrados -ya que ambos formarán parte de la edificación al ser convertidos en monumentos-, como para el lector. Por una parte, la prueba se dispone para que Amadís de Grecia solucione el conflicto, pero será incapaz debido a su falta de lealtad al debatirse en amores por dos damas: Lucela y Niquea. De ahí que Amadís de Gaula aparezca para la resolución de esta ordalía amorosa liberando a Niquea de postrarse como una estatua. La disposición de edificación mágica responderá a la nueva concepción sobre el amor que desea transmitir Silva sobre el trabajo que implica conseguir al objeto amado y al entrelazamiento que se establece entre el fundador del linaje y la nueva generación, y, por otra parte, la complicación de esta aventura mágica radicará en los personajes secundarios que aparecen y que servirán de pretexto para otorgar mayor dramatismo al episodio. Por ejemplo, Montón de la Liça se presenta como un oponente, quien ayudado por un anillo mágico es capaz de guardar la entrada de la ordalía por mucho tiempo hasta la llegada de Amadís para la liberación total del encantamiento, al menos en el caso de Niquea. En cambio, en «La torre del Universo» se dará cuenta de la conversión al cristianismo de Amadís de Grecia, quien después de «leer» su historia y el lugar de donde proviene, aceptará la religión cristiana como suya. Y es que lo allí representado por obra de los tres magos -Alquife, Urganda y Zirfea- permitirá el acceso del caballero a un conocimiento total sobre sí mismo, con lo cual, como señala Navarro, esta edificación mágica se convierte en una naturaleza dinámica, a pesar de su estatismo, al contener la capacidad de modificar una visión de mundo. Estamos ante un reconocimiento a partir de una representación de proyección identitaria, ya que Amadís de Grecia logrará conocer y aprehender su individualidad al observarse en las paredes de la torre. De esta forma, el ars narrandi con el cual se configura este par de aventuras resulta ilustrativo para comprender la innovación y el manejo de un lugar común por parte de Feliciano de Silva en los libros de caballerías como es la magia y las edificaciones creadas para el desarrollo de aventuras, pues ha logrado otorgar a este par de episodios, según Navarro, originalidad y soluciones que dependen en todo momento de los personajes involucrados como entidades movibles y generadores de acción. 
El manejo de Feliciano de Silva de todo tipo de materiales literarios para construir episodios singulares en sus novelas de caballerías será un rasgo esencial en este escritor y que lo posicionará por encima de otros autores, como demuestra Alberto del Río Nogueras, quien en «Una burla de Feliciano de Silva sobre el hombre salvaje en la Tercera parte del Florisel de Niquea» resalta la composición de un episodio cómico: una treta realizada por Fraudador de las Ardides, cuyo principal eje constitutivo es la suma de la sociabilidad curial (a manera de falsos recaudos y el arte de motejar) en función de la ciencia del blasón. El hombre salvaje y su cosificación en la heráldica permitirán dar cuenta de los alcances creativos e integradores de Silva por unir materias del pensamiento cultural del momento. Del Río Nogueras parte del episodio en que aparece la burla fraguada por Fraudador de las Ardides, cuando con ayuda de sus hermanas logra hacer chanza de los ancianos Moncano y Barnarán, para elaborar una lectura sobre el tratamiento del hombre salvaje en dicha aventura y sobre la representación artística del asalto al Castillo del Amor realizado por este personaje, representación que trasciende a objetos artísticos y decorativos propios de la cultura renacentista. Estas figuraciones representan la adaptabilidad del pensamiento cultural del momento a distintos soportes, y una muestra admirable será la representación del motivo en una vidriera alemana con las armas de la familia Huppe. El uso de materiales literarios conocidos con un halo de originalidad, adecuados a un trasunto cómico y burlesco, delinea los tratamientos modernos que se ofrecen de la imagen tradicional del hombre salvaje y los alcances significativos de éste.

Susana Gil-Albarellos Pérez-Pedrero ( «Estrategias de enunciación en la literatura del siglo XVI: algunos ejemplos en la caballería literaria») posiciona los libros de caballerías como un cimiento y germen para la creación de la novela moderna, llamando la atención sobre la necesidad de ver o captar en la práctica de este género una suerte de teorización de la novela. La enunciación narrativa, eje focal de este trabajo, puntualiza, según la autora, las posibilidades que ofrecían a los escritores de este género la comprensión e interpretación sobre el manejo de los límites de la mimesis a partir de la frontera entre historia y ficción; una dicotomía que permitió la ruptura de la posición que ocuparía el narrador, el escritor de la historia del caballero y el editor final (autor verdadero del libro de caballerías) en la composición del texto, pues este juego de voces hace compleja la perspectiva y los sentidos significativos de lo relatado. Desde este postulado, Gil-Albarellos estudia los momentos en que el autor se convierte en un personaje para solucionar que la escritura del libro sea completada (Amadís de Grecia y Olivante de Laura), la valoración de la anonimia en títulos fundamentales del ciclo de los Palmerines, y aun, más allá, la naturaleza de un discurso elaborado por una autora -como indican los paratextos del primer libro del ciclo y las implicaciones culturales y sociales, además de literarias-, que significó la materialización del Cristalián de España. Por tanto -se concluye en este artículo-, los distintos niveles de ficcionalización que aparecen en los libros de caballerías colocarían al autor como una entidad más moderna de lo que se piensa para este género literario, ya que la manera en que se plantea la elaboración de las historias narradas, además de la posición del escritor como una entidad movible, tanto dentro como fuera de la ficción, marcarán la pauta de lo realizado por Cervantes durante el siglo XVII.

La presencia femenina en los libros de caballerías se convierte crucial en varios episodios del género, donde las mujeres dan cuenta de una preceptiva sentimental generalmente idealizada, pero que, como nos muestra Federica Zoppi («Educación sentimental, humorismo y nuevos modelos femeninos: Plaerdemavida (Tirant), Triola (Platir) y otras doncellas confidente en libros de caballerías») se enriquece al incorporar un sentido cómico y humorístico para el desarrollo de acciones transgresoras y despreocupadas. Acciones en que las mujeres serán protagonistas de una apertura manifiesta al campo de la sexualidad y el erotismo. Después de un recorrido a lo largo de los princi- 
pales roles femeninos representados en varios títulos de los libros de caballerías -amiga, medianera y educadora sentimental-, será en este último paradigma en el que Zoppi se centre y resalte la importancia de las mujeres subversivas. Para ello hace un exhaustivo repaso de las intervenciones de Plaerdemavida en Tirant lo Blanc y de Triola en Platir. Ambas, además de desarrollar lo esperado en personajes mediadores entre los amores de los protagonistas, instan tanto al caballero como a la dama a llevar más allá su relación; esto, con la finalidad de incrementar su deseo corporal en todo momento. La posibilidad de encontrarse $-\mathrm{y}$ «entrelazarse $\gg-$ se facilita mediante una serie de estrategias eróticas en que se podría permitir todo (empezando por el «falso defenderse» ante un arrebato de posesión carnal): un juego de cortejo amoroso en que se echará mano a todo lo que se encuentre a su alcance para permitir consumar el amor entre los amantes. De esta manera, Zoppi demuestra que en la figura femenina de los libros de caballerías también tiene cabida una representación moderna e innovadora, un prototipo de mujer sensual que responde a su propia naturaleza («una perspectiva naturalista»), configuración de un personaje y discurso en que conviven la lujuria y la comicidad, ofreciendo una alternativa que al final sigue respondiendo a la legitimidad de la relación amorosa en el marco del amor cortesano.

El segundo apartado del monográfico se inicia con el trabajo de Rafael Rodríguez Victoria ( $\ll$ Política de la riqueza en el Libro del cavallero Zifar»), quien evidencia la importancia de que se configure -y podamos percibir y analizar- un programa de política económica en el Zifar, que consiste en mostrar por medio de la ficción el uso adecuado de la riqueza que representan los bienes materiales, desde un punto de vista político-social y desde otro meramente individual, acorde con los valores morales personales, que son los que principalmente intentan hacer mella en los receptores de esta obra. Porque será gracias al uso prudente de las «buenas costumbres» como se irá desprendiendo a lo largo del libro que la hacienda puede acumularse, tanto externa como internamente. Por lo tanto, y como demuestra Rodríguez en todo momento, la adquisición de posesiones materiales, y la legitimidad de mantenerlas o incrementarlas -diferente, dependiendo de la manera en que fueron conseguidas- implican una férrea armonía entre el ser y el quehacer del gasto. El autor realiza, así, un análisis pormenorizado de la sección de los «Castigos del rey Mentón», en donde se programa y va exponiendo la necesidad de poseer las adecuadas cualidades para conservar e incrementar las ganancias. Franqueza, mesura, generosidad, justicia y sabiduría son las principales virtudes que visualizan el buen empleo de lo material y las guías de comportamiento y de acción que se pondrán en práctica en las aventuras de Roboán. La perspectiva crítica de Rodríguez Victoria pone sobre el tintero una de las preocupaciones esenciales del proyecto didáctico del Zifar, centrándolo en uno de los objetivos más relevantes y significativos: el respaldo moral a la gestión de la posesión de bienes («política de la riqueza») para la conservación del poder personal, pero también para el buen mantenimiento del reino.

Los libros de caballerías, reflejo de la sociedad de su tiempo, podían funcionar en ocasiones como atractivos catálogos de moda. No olvidemos que los principales destinatarios y muchos consumidores de este género procedían del estamento de la nobleza, por lo que no caerían en saco roto las alusiones a las vestimentas, a sus significados en acontecimientos especiales (fiestas, encuentros diplomático, entre otros) y los detalles de los accesorios que portaban tanto mujeres como hombres de ficción, remedo de la cotidianidad cortesana. Andrea Flores García ( $\ll$ Destellos de realidad a través de la vestimenta: la influencia de la moda europea del siglo XVI en algunos libros de caballerías hispánicos») aborda en su trabajo las trazas en la ficción de caballerías de distintas vestimentas, así como de su manufactura y lucimiento. Los libros dan cuenta de la evolución que sufrieron las formas de vestir a finales del siglo XV y durante toda la centuria siguiente. Cada monarca, como detalla 
Flores, introducía una moda específica en territorio hispano, desde la conquista del territorio musulmán hasta la anexión de territorios que respondían a una tradición de prendas centroeuropeas y flamencas, incluyendo luego incluso las utilizadas en el Nuevo Mundo. De ahí que, según la autora, los colores de las telas, las formas y las posiciones de determinados accesorios, constituyan un conjunto ostentoso que adquiere un papel determinante tanto en la configuración de las relaciones entre personajes -amorosas, sin más-, cuanto de la identidad de cada uno de estos, al transmitir significados acordes con las acciones bélicas o caballerescas, cortesanas o festivas, que desarrollan en determinados episodios, como festividades. Flores también establece una relación entre las imágenes de los retratos de los monarcas y las prendas utilizadas por algunos personajes de ficción, una correspondencia que da cuenta del ir y venir de la forma de vestir y de la cultura que representan estas. Los grabados del impreso de 1526 del Amadís de Gaula, caracterizando a la dama por su trenzado, ofrecerían, en ese sentido, un magnífico ejemplo de esa conexión.

Uno de los temas de más honda preocupación durante la temprana modernidad, a causa de los cambios del paradigma religioso, fue el del libre albedrío y los alcances del individuo para ejercerlo. Sobre esta materia se centra el trabajo de Katarzyna Setkowicz ( $\ll$ Los caballeros andantes en la obra de Feliciano de Silva: entre la tolerancia y el relativismo religioso»), quien ve en la ficción de caballerías una posible respuesta a esta apertura de la fe. La autora, partiendo del presupuesto de la tolerancia religiosa presente en algunos libros de caballerías (Palmerín de Olivia y Lepolemo), demuestra cómo en las novelas de caballerías de Silva se manifiesta un cambio en cuanto a la percepción de la fe y a la existencia de una religión única que sirva de modelo de comportamiento. En el Lisuarte de Grecia, continuando con lo postulado por Rodríguez de Montalvo en el inicio del ciclo amadisiano, se manifiesta el predominio de la idea de cruzada y de transmitir una supuesta creencia verdadera en territorios no cristianos, pero será en la siguiente entrega, Amadís de Grecia, cuando se perciba una sensible mudanza. Setkowicz rastrea en esta continuación del ciclo amadisiano lo que para ella corresponde a la mentalidad de un autor que defiende un orden del mundo a partir de la idea de que el «respeto» hacia el otro constituye el centro de los valores humanos. La capacidad del individuo por discernir y decidir el sentido de sus acciones no responderá, por tanto, a la defensa de una ley predeterminada. Ejemplo de esto sería el protagonista, Amadís de Grecia, quien, a pesar de su juventud y a profesar el paganismo al inicio de la historia, es visto por otros personajes como poseedor de un alto conocimiento y comprensión hacia lo externo, al respetar a la persona y no tanto a su fe religiosa; se nos presenta movible y susceptible al cambio, de acuerdo con el contexto y no delimitado de antemano por una creencia. De ahí, que para conocer a su amada recurra al uso del disfraz femenino, un cambio de identidad que le permita acceder al amor de Niquea. Con esta metamorfosis, según la autora, nos hallamos frente a una variación del paradigma de la devoción, porque el fervor religioso cimentado por la libertad de decisión se convertirá en una «religión de amor» para y por el individuo. Y, así, los protagonistas de las siguientes continuaciones del ciclo amadisiano (Florisel de Niquea, Falanges de Astra o Rogel de Grecia) impondrán como valor máximo de actuación al amor, único modelo de sacralización, y no a otro sistema de creencias absolutas, que ha dejado de ser ejemplar.

Por último, y como cierre de este monográfico, Simon Kroll ( «El poder del sonido: El Jardín de Falerina, comedia caballeresca de Calderón») analiza el concepto pitagórico de la armonía universal a través del sonido y del sentido de audición, centrándose en la transposición caballeresca del hechizo realizado por Falerina para obtener el amor de Rugero, en la comedia de Calderón de la Barca, El jardín de Falerina. Según Kroll, la sonoridad presente en el teatro mitológico y caballeresco se presta para la realización de un juego escénico particular. Siguiendo el Timeo de Platón y 
lo expuesto en la traducción de este texto por Ficino, las resonancias amorosas producen ciertos efectos sobre el alma y el cuerpo de quien escucha, y de ahí que el espacio natural, representado por el jardín, sea el escenario perfecto para el hechizo de la maga hacia el caballero. De esta manera, la voz, el ritmo y la melodía de lo pronunciado y cantado por Falerina, como demuestra Kroll, con el auxilio de la efectiva asonancia en -í, ayuda a la materialización de las emociones. La afectación de la psique humana mediante el sonido demarcará el aparato espectacular y dramático de la puesta en escena. La interpretación de Calderón de la Barca sobre este episodio caballeresco, examinada en función del significado de lo acústico, nos deja entrever la capacidad que poseía el autor para hacer representable la lectura de sus versos: espacio, voz y espectacularidad se entrelazan para manifestar una nueva versión de un texto anterior.

La literatura de caballerías fue uno de los géneros de ficción más importantes en la temprana modernidad, por su adaptabilidad a un contexto cambiante y por las implicaciones que conllevaban no sólo el hecho de contar la historia de un caballero andante, sino el procurar una reflexión sobre los problemas que las convenciones literarias podrían aportar al momento de su composición. Además, los temas que constituían la materia caballeresca sobrepasaban lo meramente ficcional para, por medio del mundo imaginario, puntualizar algunos aspectos de la realidad, y poner en duda la funcionalidad o no de determinados motivos dentro de una cotidianidad histórica que se trataba de reflejar o idealizar. Los trabajos aquí reunidos permiten aunar e integrar, gracias a los análisis de los investigadores, una muestra del pequeño universo que los libros de caballerías y las comedias caballerescas conformaron. Aún falta mucho - parecen retarnos- por decir.

Por último, quiero agradecer a Rafael Beltrán, quien en todo momento apoyó la idea de este monográfico, por su generosidad y empatía durante el proceso de materialización de este proyecto. De igual forma, quiero extender mi agradecimiento a cada uno de los participantes del mismo.

\section{Bibliografía}

Burke, Peter (2016), El sentido del pasado en el Renacimiento, Madrid, Akal.

Cardim, Pedro (ed.) (2012), Polycentric Monarchies: How did Early Modern Spain and Portugal Achieve and Maintain a Global Hegemony?, Brighton, Sussex Academic Press.

Cuesta Torre, M. ${ }^{a}$ Luzdivina (2002), «La realidad histórica en la ficción de los libros de caballerías», en Libros de caballerías (De Amadís al Quijote). Poética, lectura, representación e identidad, ed. de Eva Belén Carro Carbajal, Laura Puerto Moro y María Sánchez Pérez, Salamanca, Seminario de Estudios Medievales y Renacentistas-Sociedad de Estudios Medievales y Renacentistas, pp. 87-109.

Eisenberg, Daniel y M. ${ }^{a}$ Carmen Marín Pina (2000), Bibliografía de los libros de caballerías castellanos, Zaragoza, Prensas Universitarias de Zaragoza.

Kagan, Richard (2009), Clio and the Crown. The Politics of History in Medieval and Early Modern Spain, Baltimore, The John Hopkins University Press.

Lucía Megías José Manuel y Emilio José Sales Dasí (2008), Libros de caballerías castellanos (siglos XVI-XVII), Madrid, Laberinto.

Marín Pina, M. ${ }^{a}$ Carmen (2011), «'Cimientos de verdad' en los primeros libros de caballerías», en sus Páginas de sueños. Estudios sobre los libros de caballerías castellanos, Zaragoza, Instituto Fernando el Católico, pp. 85-100. 
(2011), «La ideología de poder y el espíritu de cruzada en la ficción de caballerías», en sus Páginas de sueños. Estudios sobre los libros de caballerías castellanos, Zaragoza. Instituto Fernando el Católico, pp. 101-125.

Martín Romero, José Julio (2019), El «Nobiliario vero» y el pensamiento aristocrático del siglo XV, Madrid - Frankfurt am Main, Iberoamericana - Vervuert.

(2017), «Pensamiento caballeresco y pensamiento cortesano en el tránsito hacia el Renacimiento», Tirant, 20, pp. 183-198.

Martínez Muñoz, Ana (2017), Corónica de don Mexiano de la Esperança, el Caballero de la Fe, Madrid, Universidad Complutense de Madrid. Tesis doctoral.

Riвот, Luis (2019), La Edad Moderna (siglos XV-XVIII), Madrid, Marcial Pons.

Rodríguez Velasco, Jesús D. (2009), Ciudadanía, soberanía monárquica y caballería. Poética del orden de caballería, Madrid, Akal.

(2008a), «Esfuerço. La caballería de estado a oficio (1524-1615)», en Amadís de Gaula: quinientos años después. Estudios en homenaje a Juan Manuel Cacho Blecua, ed. José Manuel Lucía Megías y M. ${ }^{a}$ Carmen Marín Pina, Alcalá de Henares, Centro de Estudios Cervantinos. (2008b), «Edades teóricas: poéticas del sujeto caballeresco», Revista de Poética Medieval, 20, pp. 67-98.

(1996), El debate sobre la caballería en el siglo XV: la tratadística caballeresca castellana en su marco europeo, Valladolid, Junta de Castilla y León. 
